\title{
Overexpression of fibroblast growth factor receptor 3 in a human thyroid carcinoma cell line results in overgrowth of the confluent cultures
}

\author{
Hiroyuki Onose ${ }^{1}$, Naoya Emoto ${ }^{1}$, Hitoshi Sugihara ${ }^{1}$, Kazuo Shimizu ${ }^{2}$ and Ichiji Wakabayashi ${ }^{1}$ \\ ${ }^{1}$ Department of Medicine and ${ }^{2}$ Department of Surgery, Nippon Medical School, 1-1-5 Sendagi, Bunkyo-ku, Tokyo 113-8603 Japan \\ (Correspondence should be addressed to N Emoto, Department of Medicine, Nippon Medical School, 1-1-5 Sendagi, Bunkyo-ku, \\ Tokyo 113-8603, Japan)
}

\begin{abstract}
Recent reports indicate that a gain-of-function mutation in fibroblast growth factor receptor 3 (FGFR-3) inhibits cell growth in the cartilaginous growth plates. These results suggest that FGFR-3 may be the receptor transducing growth inhibitory signals. Using reverse transcription-PCR we examined seven papillary thyroid carcinomas to determine FGFR-3 expression. Six out of the seven papillary carcinomas expressed FGFR-3. To clarify the role of FGFR-3 in thyroid carcinoma, FGFR-3 was overexpressed in an established human papillary thyroid carcinoma cell line. High levels of FGFR-3 protein were identified in cells stably transfected with the vector containing FGFR-3 cDNA. The specific binding of ${ }^{125}$ I-FGF-2 of these cells was threefold higher than that of control cells. Growth rates of cells overexpressing FGFR-3 were similar to those of control cells. However, cells overexpressing FGFR-3 continued to grow beyond the density at which control cells stopped proliferating. These results suggest that FGFR-3 in thyroid carcinoma is not involved strongly in the cell proliferation mechanism but may contribute to the malignant extension of some of the carcinomas by modifying cell contact signaling.
\end{abstract}

European Journal of Endocrinology 140 169-173

\section{Introduction}

Fibroblast growth factor-2 (FGF-2), which promotes angiogenesis and stimulates thyroid cell growth in vitro, has been isolated from thyroids $(1-5)$. Several reports have indicated that FGF-2 is increased in human papillary thyroid carcinoma (6-8). Recently, we found that intra-tissue extracellular matrix-free FGF-2 is also increased in human papillary thyroid carcinoma and Graves' disease-affected thyroid (9).

Expression of fibroblast growth factor receptors (FGFR) is required for the response of cells to FGF-2. Four human genes that encode FGFRs (FGFR-1, -2, -3 and -4$)$ have been identified $(10,11)$. They have similar structures, consisting of three immunoglobulin (Ig)-like domains in the extracellular portion and two tyrosine kinase domains in the intracellular portion. Shingu et al. indicated that FGFR-1 was detected by immunohistochemical methods in most papillary thyroid carcinomas (12), and Thompson et al. showed that FGFR-1 was elevated in thyroid hyperplasia (13).

In the present study, we found that papillary thyroid carcinoma expressed FGFR-3. Recent reports indicate that a gain-of-function mutation in FGFR-3 inhibits cell growth in the cartilaginous growth plates and results in chondrodysplasia (14-19). These results suggest that
FGFR-3 may be the receptor transducing growth inhibitory signals. To examine the role of FGFR-3 in thyroid carcinoma, we overexpressed FGFR-3 in an established papillary thyroid carcinoma cell line (20) and investigated its effect on cell growth.

\section{Materials and methods}

\section{Materials}

Bovine calf serum was obtained from Nakarai Company (Kyoto, Japan). Ham's F-12 medium was purchased from Flow Laboratories (McLean, VA, USA), and the multiwell tissue culture plates were from Costar (Cambridge, MA, USA). Recombinant human FGF-2 was kindly supplied by Dr L Cousens (Chiron Corporation, Emeryville, CA, USA). Bolton-Hunter labeled human recombinant basic FGF (FGF-2) $\left({ }^{125} \mathrm{I}-\mathrm{bFGF} ; 1200-1300 \mathrm{Ci} / \mathrm{mmol}\right)$ was purchased from New England Nuclear (Boston, MA, USA).

\section{Human thyroid tissues and tumors}

Seven papillary thyroid carcinomas and adjacent normal thyroid tissues were obtained at thyroidectomy. 
These samples were cut into small pieces, frozen by liquid nitrogen, and stored at $-80^{\circ} \mathrm{C}$ until analysis.

\section{Reverse transcription-PCR (RT-PCR) for MRNA analysis}

Total RNA was extracted using the guanidinium isothiocyanate method (21). One microgram was reverse transcribed using $2.5 \mathrm{U}$ murine leukemia virus reverse transcriptase. The oligonucleotide primers used to identify the first Ig-like domain of FGFR-3 were 5'GGGGCCCACTGTCTGGGTCAAG-3' and 5'-GTCTTCGTCATCTCCCGAGGAT-3' as described by Zhao et al. (22) and Abbass et al. (23). PCR reactions were performed in a final volume of $100 \mu \mathrm{l}$ containing $2 \mathrm{mmol} / \mathrm{l} \mathrm{MgCl}_{2}$, $500 \mathrm{mmol} / \mathrm{l} \mathrm{KCl}, 100 \mathrm{mmol} / \mathrm{l}$ Tris$-\mathrm{HCl}$, and $2.5 \mathrm{U}$ Taq polymerase. Primers were added to a final concentration of $0.5 \mu \mathrm{mol} / \mathrm{l}$. Reaction conditions were as follows: an initial denaturation at $94^{\circ} \mathrm{C}$ for $3 \mathrm{~min}$, followed by 35 cycles of $94^{\circ} \mathrm{C}$ for $1 \mathrm{~min}$, annealing at $56-60^{\circ} \mathrm{C}$ for $2 \mathrm{~min}$, extension at $72^{\circ} \mathrm{C}$ for $1 \mathrm{~min}$, and a final cycle of $72{ }^{\circ} \mathrm{C}$ for $10 \mathrm{~min}$. The products were visualized by electrophoresis on $1 \%$ agarose gels and ethidium bromide staining and verified by Southern hybridization with complementary DNA (cDNA) of human FGFR-3.

\section{TC cells}

Human papillary thyroid carcinoma cell line (TC cell) (20) cells were cultured in modified Ham's F-12 medium supplemented with $5 \%$ calf serum (growth medium) at $37^{\circ} \mathrm{C}$ in a humidified atmosphere $\left(95 \%\right.$ air, $\left.5 \% \mathrm{CO}_{2}\right)$. The cells were seeded at an initial density of $1.0 \times 10^{5}$ cells per well in 12-well culture plates containing $0.75 \mathrm{ml}$ growth medium and cultured for $1-16$ days. The medium with or without FGF-2 $(10 \mathrm{ng} / \mathrm{ml})$ was renewed every other day. After washing the culture with the medium and dissociating the cells by treatment with $0.25 \%$ trypsin, the cell number was determined with a Coulter counter.

\section{Transfections}

Complementary DNA of human FGFR-3 was generously provided by Dr Mike Hayman (State University of New
York, Stony Brook, USA) (24). The HindIII-KpnI fragment of FGFR-3 cDNA was subcloned into the pcDNA3 expression vector (Invitrogen, Carlsbad, CA, USA). A schematic diagram of the fragment including the sequence of the $5^{\prime}$ untranslated part of the clone, which has not been published, is shown in Fig. 1. The unpublished $5^{\prime}$ sequence has an ATG start codon but the same reading frame results in a TGA termination codon before the open reading frame for FGFR-3. Seventy-two hours prior to transfection, TC cells were plated at a density of $2 \times 10^{5}$ cells into $35 \mathrm{~mm}$ dishes. The cells were transfected with $1 \mu \mathrm{g}$ of the vector using lipofectamine (Gibco BRL, Grand Island, NY, USA). Geneticin $(500 \mu \mathrm{g} / \mathrm{ml})$ (Gibco BRL)-resistant colonies were expanded into cell lines.

\section{Immunoblotting}

Confluent cultures of TC cells in $100 \mathrm{~mm}$ dishes were collected with a cell scraper and solubilized with RIPA buffer (phosphate buffered saline with 1\% NP40, 0.5\% sodium deoxycholate, and $0.1 \%$ SDS). The samples were mixed with $2 \times$ Laemmli buffer and subjected to $4-20 \%$ gradient SDS-polyacrylamide gel electrophoresis. Samples were blotted from gels onto supported nitrocellulose membranes (Amersham Life Science, Amersham, Bucks, UK) by electrotransfer. Blots were then incubated with the anti-FGFR-3 antibody (Santa Cruz Biotechnology, Santa Cruz, CA, USA) followed by incubation with goat anti-mouse IgG conjugated with alkaline phosphatase. Immunoreactive proteins were revealed by alkaline phosphatase conjugate substrate kit (BioRad Laboratories, Richmond, CA, USA).

\section{${ }^{125}$ I-FGF-2 binding to TC cells}

${ }^{125}$ I-FGF-2 binding to TC cells was examined as described previously (5). Briefly, confluent cultures of TC cells in 12-well culture plates were washed with PBS, and the medium was changed to F-12 medium containing $0.15 \%$ gelatin and $25 \mathrm{mmol} / \mathrm{l}$ HEPES, $\mathrm{pH}$ 7.4. ${ }^{125}$ I-FGF-2 $\left(0.5-1.0 \times 10^{5}\right.$ c.p.m. $\left./ \mathrm{ml}\right)$ with or without unlabeled FGF-2 was added to the culture, and the cells were incubated for three hours at $4{ }^{\circ} \mathrm{C}$. At the end of the incubation, after the $2.0 \mathrm{~mol} / \mathrm{l} \mathrm{NaCl}$ wash $(\mathrm{pH}$

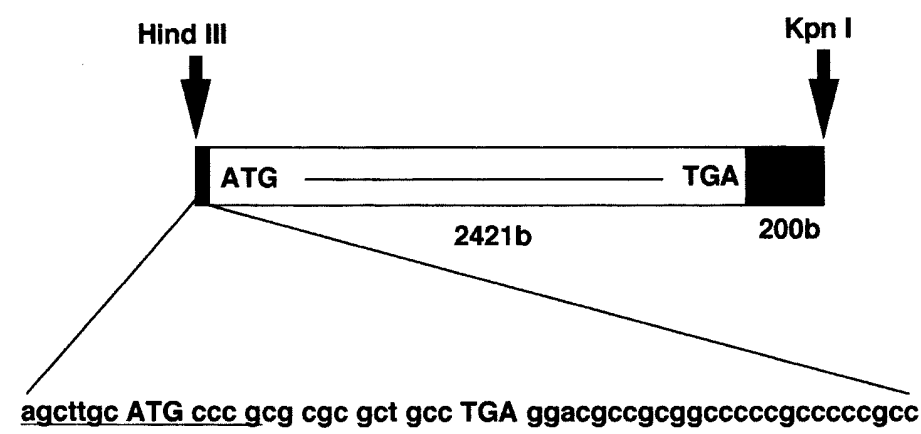

Figure 1 Schematic diagram of the HindllIKpnl fragment of human FGFR-3 cDNA used in the expression experiment. The open box represents the open reading frame and the closed box indicates the non-coding region. The nucleotide sequence which has not been published is underlined. 
Figure 2 Southern hybridization analysis (lower panel) of RT-PCR products (upper panel: ethidium bromide staining) of FGFR-3 mRNA from human thyroids. RNA was extracted from normal human thyroid (lane 1), and human papillary thyroid carcinoma (lanes 2-8) and TC cells (lane 9), as described in the text.

7.4), the cells were solubilized with $1.0 \mathrm{~mol} / \mathrm{l} \mathrm{NaOH}$, and an aliquot of the solution was used to determine radioactivity. We estimated the nonspecific high-affinity binding of ${ }^{125} \mathrm{I}-\mathrm{FGF}-2$ by adding $1.0 \mu \mathrm{g} / \mathrm{ml}$ unlabeled FGF-2 to parallel cultures that were incubated under the same conditions, and we subtracted this value from the binding values obtained in all the high-affinity binding studies.

\section{Results}

Figure 2 shows the expression of FGFR-3 in papillary thyroid carcinoma and normal thyroid. Normal thyroid and six out of the seven papillary carcinomas expressed FGFR-3.

To investigate the role of FGFR-3, we overexpressed FGFR-3 in an established papillary thyroid carcinoma cell line (TC). Wild type TC cells expressed FGFR-1 and -2 mRNA (data not shown) in addition to FGFR-3 (Fig. 2). FGF-2 stimulated wild type TC cell growth in three days of culture (Fig. 3). Figure 4 shows the Western blotting of FGFR-3 extracted from TC cells stably transfected with the FGFR-3 cDNA or control

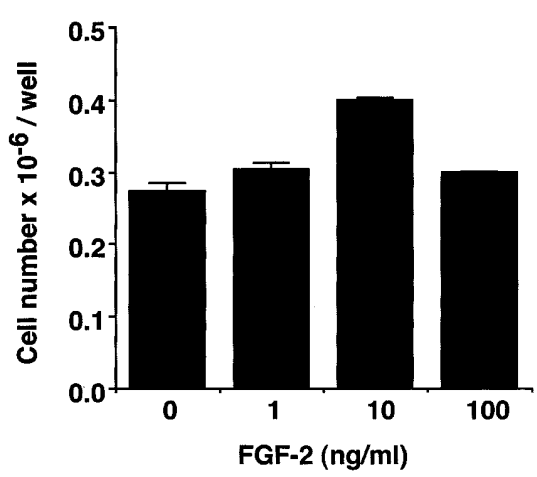

Figure 3 Effect of FGF-2 on TC cell growth. TC cells were cultured with the indicated concentrations of FGF-2 for three days. The cell number was determined as described in the text. Values are means \pm S.D. of triplicate wells from one of three experiments. vector. A 12-kDa FGFR-3 band was barely detectable in extracts from control cells transfected with the vector (clones TCpc77-1, -2, -3, -4, and -5), but markedly higher amounts of the FGFR-3 band were observed in extracts from TC cells transfected with FGFR-3 (clones TCR377-2 and TCR377-3). One clone transfected with FGFR-3 (TCR377-1) did not show high levels of FGFR-3 expression. ${ }^{125}$ I-FGF-2 binding to clones TCR 377-2 and -3 was threefold higher than that to the control cells and TCR 377-1 cells (Fig. 5). These results indicate that clones TCR 377-2 and TCR377-3 overexpressed FGFR-3 on their cell surfaces.

Next, we examined the growth rate of TC cells stably transfected with FGFR-3 or control vector. In the presence of FGF-2 $(10 \mathrm{ng} / \mathrm{ml})$, the growth rates of clones TCR377-2 and TCR377-3 were not different from the growth rates of the control cells (TCpc77-1, -2 , and -5). However, cells overexpressing FGFR-3 continued to grow beyond the density at which control cells stopped proliferating. At 15 days of culture, the cells reached a $75 \pm 16 \%$ (mean \pm S.e.) greater cell density $(P<0.01)$ than control cells (Fig. 6). After that, we could not estimate cell number precisely because of increased floating cells. In the absence of FGF-2, the growth rates and final cell density of TC cells overexpressing FGFR-3 were not significantly different from those of the control cells (data not shown). Similar results were obtained with two different clones (TCR 377-7 and TCR327-6) overexpressing FGFR-3.

\section{Discussion}

In the present study, we observed that normal thyroids and most papillary thyroid carcinomas expressed FGFR-3. Shingu et al. (12) detected FGFR-1 in papillary thyroid carcinomas immunohistochemically. Although FGF-2 stimulates thyroid cell growth in vitro, it is not known whether the FGF-2 cell proliferation signal is transduced by FGFR-1, -3 or both. On the other hand, recent reports of gain-of-function mutations in FGFR-3 suggest that FGFR-3 could be a growth inhibitory receptor $(17,19)$. We overexpressed FGFR-3 in an established 


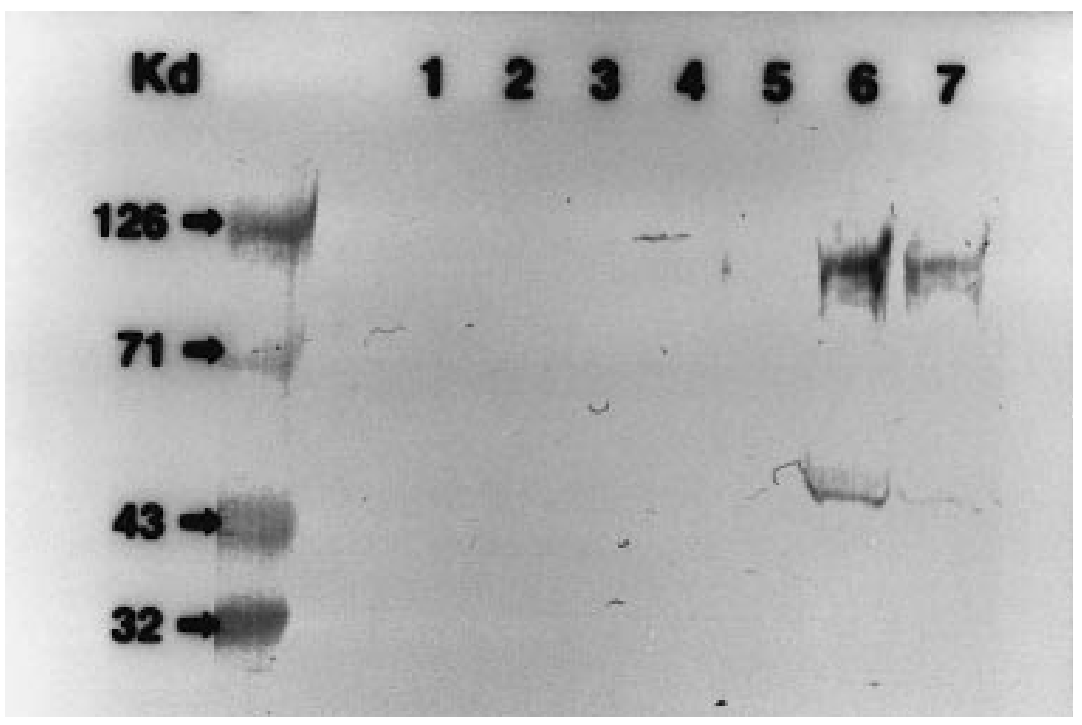

Figure 4 Western blotting of FGFR-3. The solubilized materials from TC cells transfected with control vector (clones TCpc77-1, -2, -3, -4, and -5 ; lanes 1-5) or vector containing FGFR3 cDNA (clones TCR377-2 and -3; lanes 6 and 7) were subjected to SDS-PAGE and immunoblotted with anti-FGFR-3 antibody as described in the text. human papillary thyroid carcinoma cell line (TC cells) to investigate the pathophysiological relevance of FGFR-3 expression in thyroid carcinoma.

TC cells are derived from human papillary cancer cells and synthesize insulin-like growth factor (IGF)-I, which stimulates growth by an autocrine mechanism (20). TC cell growth is also stimulated by FGF-2 (Fig. 3). This indicates that TC cells have the FGF-2 response system and are a good model system for investigating the role of FGFRs. As shown in Figs 4 and 5, overexpression of FGFR-3 in TC cells is markedly higher than in control cells, and it is possible that overexpression of FGFR-3 drastically changes the balance in expression of FGFRs. Thus, we examined the role of FGFR-3 in thyroid carcinoma growth in the present study.

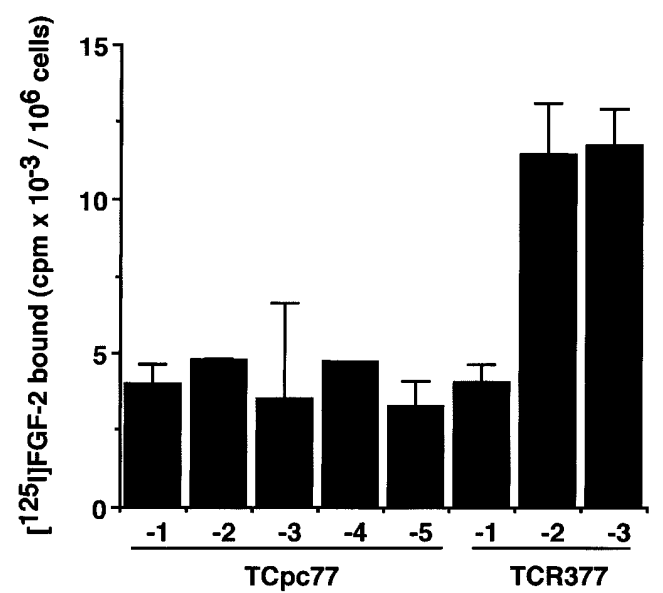

Figure 5 The binding of ${ }^{125} \mathrm{I}-\mathrm{FGF}-2$ to TC cells. TC cells transfected with control vector (clones TCpc77-1, $-2,-3,-4$ and -5 ) or vector containing FGFR-3 cDNA (clones TCR377-1, -2, and -3) were incubated with ${ }^{125} \mathrm{I}-\mathrm{FGF}-2$ for three hours at $4^{\circ} \mathrm{C}$. The high-affinity binding of ${ }^{125}$ I-FGF-2 was determined as described in the text.
Overexpression of FGFR-3 in TC cells had no effect on the growth rate of the cells. Naski et al. (18) showed in a pro B cell line that normal FGFR-3 expression is weak and less efficient than FGFR-1 in the mitogenic response to FGF, although activation of FGFR-3 promotes cell proliferation. On the other hand, Su et al. (17) indicated that the rate of DNA synthesis or colony-formation efficiency in $293 \mathrm{~T}$ cells was reduced significantly by expression of an FGFR-3 gain-of-function mutant, suggesting FGFR-3 is an inhibitory receptor. These results suggest that the function of FGFR-3 is diverse in various tissues. Although it is possible that other FGFRs may affect the result, it seems reasonable to conclude that FGFR-3 in thyroid carcinoma is not involved strongly in the cell proliferation mechanism.

We found that overexpression of normal FGFR-3 in TC cells caused overgrowth of the confluent cultures.

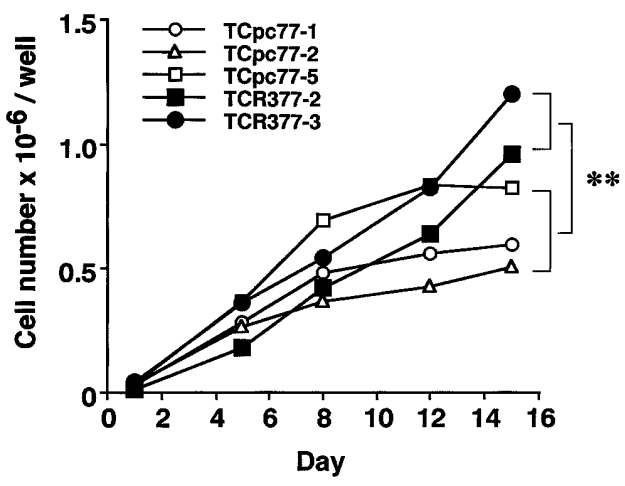

Figure 6 Comparison of the growth curves of TC cells overexpressing FGFR-3 (clones TCR377-2 and -3) or TC cells transfected with control vector (clones TCpc77-1, -2, and -5). The cells were incubated in the medium containing $5 \%$ calf serum with $10 \mathrm{ng} / \mathrm{ml}$ FGF-2. The medium was changed and the treatment was renewed every other day. $P<0.01$. 
This effect must be due to overexpression of FGFR-3 stimulated by FGF-2, since it was not observed in the absence of FGF-2 or in the control cells. This suggests that FGFR-3 may be involved in contact inhibition. Because we examined one particular cell line in the present study, further studies will be necessary. However, this result suggests at least that FGFR-3 may contribute to the malignant extension of some papillary thyroid carcinomas by reducing the contact inhibition. The precise nature of the contact inhibition is not clear at this time. Cell contact-dependent signaling includes juxtacrine peptides, adhesion molecules and cell junction proteins (25). The effect of FGFR-3 overexpression on these factors is now under investigation in our laboratory.

In summary, we found FGFR-3 expression in thyroid carcinoma and normal thyroid. Overexpression of FGFR-3 in TC cells suggests that FGFR-3 may promote the malignant proliferation of thyroid carcinomas by altering contact inhibition. However, it is not clear whether the balance of FGFR-1 and -2 has any pathophysiological relevance in the growth of thyroid carcinoma. To address this question, experiments with combined overexpression of FGFRs in TC cells are now in progress in our laboratory.

\section{Acknowledgements}

The authors wish to thank Dr Shin-Ichiro Takahashi and Dr Fumihiko Hakuno (The University of Tokyo, Japan) for their support and encouragement. This work was supported by a Grant-in-Aid for scientific research from the Japanese Ministry of Education, Science and Culture, and a grant from the Foundation for Growth Science (Japan).

\section{References}

1 Emoto N, Isozaki O, Arai M, Murakami H, Shizume K, Baird A et al. Identification and characterization of basic fibroblast growth factor in porcine thyroids. Endocrinology 1991128 58-64.

2 Emoto N, Isozaki O, Arai M, Murakami H, Shizume K, Tsushima T et al. An immunoneutralizing anti-basic-FGF antibody potentiates the effect of basic FGF on the growth of FRTL-5 thyroid cells. Annals of the New York Academy of Sciences 1991638 456-458.

3 Logan A, Black EG, Gonzalez A, Buscaglia M \& Sheppard MC. Basic fibroblast growth factor: an autocrine mitogen of rat thyroid follicular cells? Endocrinology 1992130 2363-2372.

4 Isozaki O, Emoto N, Tsushima T, Sato Y, Shizume K, Demura H et al. Opposite regulation of deoxyribonucleic acid synthesis and iodide uptake in rat thyroid cells by basic fibroblast growth factor: correlation with opposite regulation of c-fos and thyrotropin receptor gene expression. Endocrinology $19921312723-2732$.

5 Emoto N, Isozaki O, Ohmura E, Shizume K, Tsushima T \& Demura H. Degradation of cell surface heparan sulfates decreases the high affinity binding of basic FGF to endothelial cells, but not for FRTL5 rat thyroid cells. Thyroid 19955 455-460.

6 Daa T, Kodama M, Kashima K, Yokoyama S, Nakayama I \& Noguchi S. Identification of basic fibroblast growth factor in papillary carcinoma of the thyroid. Acta Pathologica Japonica 1993 $43582-589$

7 Kodama M, Daa T, Kashima K, Yokoyama S, Nakayama I \& Noguchi S. Immunohistochemical localization of acidic and basic fibroblast growth factors in human benign and malignant thyroid lesions. Japanese Journal of Clinical Oncology 199424 66-73.

8 Eggo MC, Hopkins JM, Franklyn JA, Johnson GD, Sanders DS \& Sheppard MC. Expression of fibroblast growth factors in thyroid cancer. Journal of Clinical Endocrinology and Metabolism 199580 1006-1011.

9 Emoto N, Onose H, Sugihara H, Minami S, Shimizu K \& Wakabayashi I. FGF-2 free from extracellular matrix is increased in papillary thyroid carcinomas and Graves' thyroids. Thyroid 19988 491-497.

10 Jaye M, Schlessinger J \& Dionne CA. Fibroblast growth factor receptor tyrosine kinases: molecular analysis and signal transduction. Biochimica et Biophysica Acta 19921135 185-199.

11 Johnson DE \& Williams LT. Structural and functional diversity in the FGF receptor multigene family. Advances in Cancer Research $1993601-41$.

12 Shingu K, Fujimori M, Ito K, Hama Y, Kasuga Y, Kobayashi S et al. Expression of fibroblast growth factor- 2 and fibroblast growth factor receptor-1 in thyroid diseases - difference between neoplasms and hyperplastic lesions. Endocrine Journal 199845 35-43.

13 Thompson SD, Franklyn JA, Watkinson JC, Verhaeg JM, Sheppart MC \& Eggo MC. Fibroblast growth factors 1 and 2 and fibroblast growth factor receptor 1 are elevated in thyroid hyperplasia. Journal of Clinical Endocrinology and Metabolism 199883 1336-1341.

14 Shiang R, Thompson LM, Zhu YZ, Church DM, Fielder TJ, Bocian $\mathrm{M}$ et al. Mutations in the transmembrane domain of FGFR 3 cause the most common genetic form of dwarfism, achondroplasia. Cell $199478335-342$.

15 Rousseau F, Bonaventure J, Legeaimallet L, Pelet A, Rozet JM, Maroteaux $\mathrm{P}$ et al. Mutations in the gene encoding fibroblast growth factor receptor-3 in achondroplasia. Nature 1994371 252-254.

16 Webster MK \& Donoghue DJ. Constitutive activation of fibroblast growth factor receptor 3 by the transmembrane domain point mutation found in achondroplasia. EMBO Journal $199615520-$ 527.

17 Su WS, Kitagawa M, Xue N, Xie B, Garofalo S, Cho J et al. Activation of stat 1 by mutant fibroblast growth-factor receptor in thanatophoric dysplasia type II dwarfism. Nature 1997386 288-292.

18 Naski MC, Wang Q, Xu J \& Ornitz DM. Graded activation of fibroblast growth factor receptor 3 by mutations causing achondroplasia and thanatophoric dysplasia. Nature Genetics 199613 233-237.

19 Deng C, Wynshaw-Boris A, Zhou F, Kuo A \& Leder P. Fibroblast growth factor receptor 3 is a negative regulator of bone growth. Cell $199684911-921$.

20 Onoda N, Ohmura E, Tsushima T, Ohba Y, Emoto N, Isozaki O et al. Autocrine role of insulin-like growth factor (IGF)-I in a human thyroid cancer cell line. European Journal of Cancer 1992 28A 1904-1909.

21 Emoto N, Walicke P, Gonzalez A, Wada E, Simmons D, Shimasaki $S$ et al. Basic fibroblast growth factor (FGF) in the central nervous system: identification of specific loci of basic FGF expression in the rat brain. Growth Factors 19892 21-29.

22 Zhao X-M, Frist WH, Yeoh T-K \& Miller GG. Modification of alternative messenger RNA splicing of fibroblast growth factor receptors in human cardiac allografts during rejection. Journal of Clinical Investigation $199494992-1003$.

23 Abbass SAA, Asa SL \& Ezzat S. Altered expression of fibroblast growth factor receptors in human pituitary adenomas. Journal of Clinical Endocrinology and Metabolism 199782 1160-1166.

24 Keegan K, Johnson DE, Williams LT \& Hayman MJ. Isolation of an additional member of the fibroblast growth factor receptor family, FGFR-3. Proceedings of the National Academy of Sciences of the USA 199188 1095-1099.

25 Fagotto F \& Gumbiner BM. Cell contact-dependent signaling. Developmental Biology $1996180445-454$.

Received 7 August 1998

Accepted 16 November 1998 